\title{
Ailanthone: A novel potential drug for treating human cancer (Review)
}

\author{
HAIXIANG DING ${ }^{1}$, XIUCHONG YU ${ }^{2}$, CHEN HANG $^{1}$, KAIJUN GAO $^{1}$, \\ XIFENG LAO ${ }^{1}$, YANGTAO JIA ${ }^{1}$ and ZHILONG YAN ${ }^{2}$ \\ ${ }^{1}$ Medical School of Ningbo University, Ningbo University, Ningbo, Zhejiang 315211; \\ ${ }^{2}$ Department of Gastrointestinal Surgery, The Affiliated Hospital of The Medical School of \\ Ningbo University and Ningbo First Hospital, Ningbo, Zhejiang 315010, P.R. China
}

Received September 12, 2019; Accepted May 5, 2020

DOI: $10.3892 / \mathrm{ol} .2020 .11710$

\begin{abstract}
Cancer is the second leading cause of death after cardiovascular disease. In 2015, >8.7 million people died worldwide due to cancer, and by 2030 this figure is expected to increase to $\sim 13.1$ million. Tumor chemotherapy drugs have specific toxicity and side effects, and patients can also develop secondary drug resistance. To prevent and treat cancer, scientists have developed novel drugs with improved antitumor effects and decreased toxicity. Ailanthone (AIL) is a quassinoid extract from the traditional Chinese medicine plant Ailanthus altissima, which is known to have anti-inflammatory and antimalarial effects. An increasing number of studies have focused on AIL due to its antitumor activity. AIL can inhibit cell proliferation and induce apoptosis by up- or downregulating cancer-associated molecules, which ultimately leads to cancer cell death. Antitumor effects of AIL have been observed in melanoma, acute myeloid leukemia, bladder, lung, breast, gastric and prostate cancer and vestibular neurilemmoma. To
\end{abstract}

Correspondence to: Professor Zhilong Yan, Department of Gastrointestinal Surgery, The Affiliated Hospital of The Medical School of Ningbo University and Ningbo First Hospital, 59 Liuting Street, Ningbo, Zhejiang 315010, P.R. China

E-mail: yanzhilong@nbu.edu.cn

Abbreviations: AIL, ailanthone; AML, acute myeloid leukemia; MMP, matrix metalloproteinase; Nrf2, NF-E2-related factor; YAP, Yes-associated protein; JAK, Janus kinase; STAT3, signal transducer and activator of transcription 3; RAF, RAF proto-oncogene serine/threonine-protein kinase; MEK, mitogen-activated protein kinase kinase; ERK, extracellular signal-regulated kinases; PI3K, phosphoinositide 3-kinase; AKT, protein kinase B; PARP, poly-ADP-ribose polymerase; mTOR, mammalian target of rapamycin; Bcl-2, B cell lymphoma-2; Bax, Bcl-2-associated X; $\mathrm{AR}$, androgen receptors; CRPC, castration-resistant prostate cancer; AMPK, AMP-activated protein kinase; CKI, CDK inhibitor

Key words: ailanthone, cancer, antitumor, apoptosis, autophagy, mechanism the best of our knowledge, the present study is the first review to describe the antitumor mechanisms of AIL.

\section{Contents}

1. Introduction

2. Natural products as antitumor drugs

3. Ailanthone (AIL) as an anti-tumor drug

4. Preclinical safety evaluation of AIL

5. Antitumor mechanism of AIL

6. Conclusions

\section{Introduction}

Cancer, as a complex disease, is the result of long-term interaction of various exogenous and endogenous carcinogenic factors (1-3). Normal cell division has a certain maximum number of divisions, and it is precisely regulated by a series of internal factors such as genes, enzymes and proteins. Tumor cells often divide uncontrollably without following the principles of normal self-limited cell division, and can invade or spread to other healthy parts of the body, leading to the formation of tumors (4). Cancer is the second leading cause of death worldwide (5). With nearly $60 \%$ of the world's population in Asia, $48.4 \%$ of new cancer cases and more than half of cancer-associated deaths $(57.3 \%)$ occur in this region, where cancer mortality is higher compared with that in other regions, such as Europe, Africa and America (5). Lung cancer has the highest morbidity and mortality rates of all cancer types in men in China (6). In China, the most common cancer types among men and women are lung and breast cancer, respectively (6). Currently, the US Food and Drug Administration has approved $\sim 150$ anticancer drugs, which are classified into either cytotoxic or targeted drugs. Cytotoxic drugs can kill cancer cells by targeting mitotic and/or DNA replication pathways, whereas targeted drugs block the growth and spread of cancer by inhibiting molecular targets associated with cancer progression and migration (7). However, targeted drugs are often more expensive, and cytotoxic drugs often have various side effects and toxicity levels. Therefore, identification and isolation of natural compounds from medicinal plants has 
received increasing attention for the development of novel anticancer drugs, with the aim overcome drug resistance and long-term survival.

\section{Natural products as antitumor drugs}

Medicinal plants have a long history of being used to treat various types of cancer. For example, numerous Asian countries, such as China, Japan and Thailand, have used traditional medicinal plants to treat cancer for thousands of years (8-10). Several of the antineoplastic drugs that have been used in a clinical setting originate from plants, some of which have significantly prolonged the survival time of patients. For example, vincristine is used to treat leukemia (11), lymphoma (12), breast cancer (13), lung cancer (14) and pediatric solid cancers (15); paclitaxel is used to treat ovarian, breast, lung, bladder and head and neck cancer (16); docetaxel is used to treat breast (17) and lung (18) cancer; and irinotecan is used to treat colorectal and lung cancer (19). In addition, a number of natural products (including evodiamine, peimine, isorhynchophylline, Coptis chinensis, ephedrine, oridonin and matrine) improve the drug resistance of cancer cells (breast cancer resistance to paclitaxel and epirubicin; gastric cancer resistance to fluorouracil; lung adenocarcinoma cell resistance to cisplatin and docetaxel; and hepatocellular carcinoma resistance to cisplatin), which is the primary cause of cancer chemotherapy failure (20). Recently, an increasing number of studies have focused on the anticancer mechanism of natural products. Wu et al (21) have reported that icariin induces apoptosis in human lung adenocarcinoma cells by activating the mitochondrial apoptotic pathway. Furthermore, lycorine has notable antitumor effects in various types of cancer, such as breast, esophageal, ovarian, prostate, melanoma and liver cancer (22). Acridone alkaloids are another class of natural products primarily obtained from Swinglea glutinosa, which has selective cytotoxicity against human prostate, lung, breast and liver carcinoma cell lines (23). In the Allium cepa assay and the yeast proliferation model, Kanchnar guggulu was evaluated for its cytotoxicity by inhibiting mitosis and anti-proliferation effects, confirming its potential in cancer treatment, and current studies have shown that it has antitumor effect $(24,25)$. In addition, it has been confirmed that the use of a standardized Chinese herbal formula (including Radix and Rizoma Ginseng, Rhizoma Atractylodis, Poriae; Radix Glycyrrhiza Preparata, Rehmannia glutinosa, Radix Paeoniae alba, Radix Angelica sinensis, Rhizoma Chuang xiong, Ramulus Cinnamomum, Semen Armeniaca amarum, Radix Platycodonois, Radix Saposhnikoviae, Fructus Jujubae, Massa Medica Fermentata, Cordyceps, RhizomaDioscoreae, Radix Ophiopogonis, Radix Bupleuri, Colla Corii asini, Semen Lablab album, Rhizoma Zingiberis, Ganoderma and Rhodiolae crenulatae) in patients with advanced lung cancer is acceptable and safe (26), therefore natural products have a broad application in the development and application of antitumor drugs.

\section{Ailanthone (AIL) as an anti-tumor drug}

Ailanthus altissima is a plant of the genus Ailanthus in the family Simaroubaceae (27). As a traditional Chinese medicine, it has a long history in China; for example, its bark, root bark and fruit have been used for the treatment of ascariasis, diarrhea, spermatorrhea, bleeding and gastrointestinal diseases (28). AIL, extracted from Ailanthus altissima, is a pentacyclic diterpene lactone compound (Fig. 1). It has notable clinical benefits in the treatment of inflammation (29), malaria (30), allergies (31), tuberculosis (32), ulcer s (33), amoeba-associated disease (34) and HIV (35) and has antitumor effects (36). Numerous in vitro studies have revealed that AIL has inhibitory effects on sever types of cancer cells, such as melanoma (37), acute myeloid leukemia $(38,39)$, bladder (40), lung cancer $(41,42)$, gastric (43), liver (44) and breast $(27,45)$ cancer, vestibular schwannomas (VS) (46), osteosarcoma (47) and prostate cancer (48). The specific antitumor mechanism of AIL is summarized in Fig 2. In addition, AIL was found to improve the resistance of prostate cancer cells and leukemia cells to MDV3100 and doxorubicin (DOX), respectively $(48,49)$. An overview of the antitumor mechanism of AIL in various types of cancer cells will be discussed in the present review.

Antitumor activity of AIL against melanoma. In 2011, a total of 9,128 melanoma deaths occurred in the United States. The overall age-adjusted melanoma death rate was 2.7 per 100,000 and the mortality rate of malignant melanin is even higher (50). It has become one of the most serious malignant tumors threatening human health (51). Liu et al (37) demonstrated that AIL inhibited cell proliferation and promoted apoptosis of B16 and A375 melanoma cells in a dose-dependent manner by downregulating the phosphoinositide 3-kinase (PI3K)/protein kinase B (AKT) signaling pathway and inducing the activation of apoptotic initiating factors. The results of their study also revealed that the number of viable cells significantly decreased with increasing AIL concentrations 24-h following incubation (37). Subsequently, the potential mechanisms were explored; AIL induced $\mathrm{G}_{0} / \mathrm{G}_{1}$ phase arrest in B16 cells and $\mathrm{G}_{2} / \mathrm{M}$ phase arrest in A375 cells, significantly increasing the apoptotic rate in a dose-dependent manner (37).

Distinct apoptotic characteristics, such as nuclear condensation, irregular contraction of chromatin and apoptotic bodies were observed in the AIL-treated B16 cells, whereas the protein expression levels of p21 were increased and the levels of cyclins E and B were decreased. These results suggested that AIL inhibited cell proliferation by regulating cell cycle-associated protein expression to block the cell cycle of melanoma cells; the expression levels of PI3K, phosphorylated (p)-PI3K and p-AKT were also decreased, indicating that AIL inhibited the activity of the PI3K/AKT signaling pathway (37). In addition, the decrease of the mitochondrial membrane potential, increase of cytochrome $\mathrm{c}$ and Apaf-1 expression and activation of caspase- 9 and -3 indicated that AIL mediated apoptosis through the mitochondrial pathway (37). Overall, these results suggested that AIL may be a potential antitumor agent to treat melanoma.

Antitumor activity of AIL against acute myeloid leukemia (AML). Acute myeloid leukemia (AML) is an aggressive, heterogeneous, myeloid malignancy. It is the most common adult acute leukemia and accounts for $\sim 80 \%$ of cases (52). microRNAs (miRNAs/miRs) are short RNA 


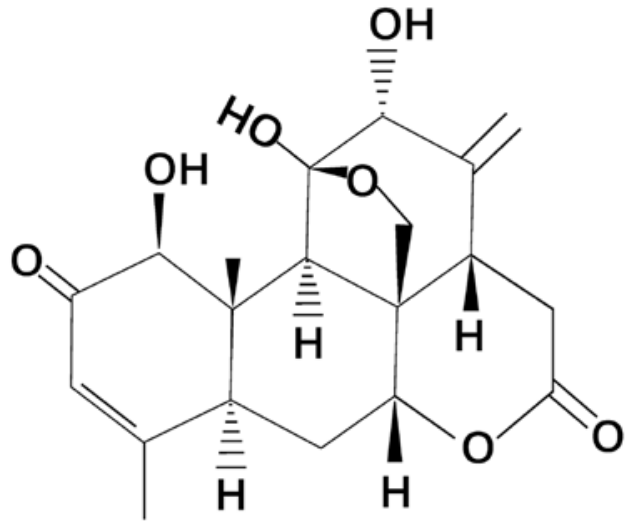

Figure 1. Molecular structure of ailanthone.

molecules that negatively regulate gene expression; miRNAs are downregulated in numerous types of solid tumors, such as gastric cancer (53), lung cancer (54) and osteosarcoma (55). Moreover, abnormal expression levels of miRNAs (miR-128a, miR-92a, miR-143 and miR-342) are associated with the development of AML (56,57). miRNA-449a is downregulated in several types of solid tumors (including gastric and liver cancer) and can regulate the expression of tumorigenesis-associated genes, such as Flotillin 2 (58) and SOX4 (59). Based on these findings, Zhang et al (38) explored the potential role of miR-449a in AML and demonstrated that AIL inhibited the activity of AML cells and induced apoptosis by targeting miR-449a. AIL inhibited cell viability in a dose-dependent manner and exerted significant inhibitory effects on tumor cell migration and invasion, possibly via the downregulation of matrix metalloproteinase (MMP)-9 and vimentin (38). In addition, AIL also notably increased the levels of cleaved-caspase-7, -3 and -9, leading to increased tumor cell apoptosis in the AIL-treatment group $(\mathrm{P}<0.05)$ (38). Further investigation reported that AIL significantly $(\mathrm{P}<0.01$ or $\mathrm{P}<0.001)$ increased the mRNA expression levels of miR-449a in AML cells. Subsequently, following transfection of a miR-449a inhibitor into AML cells, the levels of cleaved-caspase-7, -3 and -9 and the apoptotic rate in the AIL-treatment group were decreased, with the latter being significant $(\mathrm{P}<0.05)$. In addition, the protein expression levels of Notch1 and 2, p-PI3K and p-AKT in the AIL-treatment group were also lower compared with those in the control group, and the inhibitor of miR-449a reversed this. These results suggested that AIL upregulated the expression of miR-449a in the Notch and PI3K/AKT signaling pathways (38). Wei et al (39) reported that AIL promoted apoptosis by inducing autophagy in HL-60 promyelocytic leukemia cells. Their results demonstrated that acidic vesicular organelles, which are one of the characteristics of autophagy, were observed in the experimental group. The protein expression levels of the autophagy-associated proteins were determined, and the results revealed that levels of Beclin-1 and light chain (LC)3-II were upregulated, while the levels of p62 and LC3-I were downregulated in a dose-dependent manner (all $\mathrm{P}<0.05$ ) (39). Therefore, these results indicated that AIL induced autophagy and that AIL may be a potential treatment for AML.
Antitumor activity of AIL against bladder cancer. Bladder cancer is one of the most common malignant tumors in the urinary system. Global cancer statistics in 2018 found that bladder cancer is more common in men, in whom it is the sixth most common cancer and ninth leading cause of cancer-associated death (5). Currently, the combination of surgery and cisplatin-based chemotherapy is the standard treatment (60); however, cisplatin-based chemotherapy is often accompanied by secondary drug resistance, which can reduce the long-term therapeutic effect and is particularly evident in invasive urothelial cancer (61). Cisplatin resistance in patients with bladder cancer is associated with overexpression of NF-E2-related factor (Nrf2), and increased Nrf2 in resistant cells has been recognized as an important factor in maintaining drug resistance (62). Nrf2 also promotes the epithelial-mesenchymal transition by downregulating E-cadherin, and knockdown of Nrf2 impairs tumor cell migration and invasion (63). Yes-associated protein (YAP) is the primary effector of the Hippo pathway, which also participates in chemotherapy resistance of bladder cancer (64). When the Hippo pathway is inhibited, YAP is transported into the nucleus and binds to transcription factors, such as transcriptional enhanced associate domains, to promote the expression of target genes (c-Myc, Cyr61 and survivin) that regulate cell proliferation, migration and survival (64). Conversely, knockdown of YAP and silencing of Nrf2 can enhance the sensitivity of bladder cancer cells to cisplatin and reduce the migration of tumor cells (62). Daga et al (40) demonstrated that AIL inhibited the proliferation and migration of bladder cancer cells by reducing the expression of Nrf2, YAP and c-Myc. Moreover, a similar effect was identified in cisplatin-resistant bladder cancer cells. The results of MTT and colony formation assays demonstrated that AIL was more effective compared with cisplatin in inhibiting the growth of $253 \mathrm{~J} \mathrm{B-V}$ and 253J bladder cancer cell lines (40). Of note, the growth inhibition rate of the cisplatin-resistant cell lines, 253J B-V C-r and 253J C-r was the same as that of the sensitive cells, confirming the cytotoxicity and antiproliferative effect of AIL. Furthermore, AIL exhibited low cytotoxicity in normal adult HK-2 renal cortex cells, indicating that the toxicity of AIL to normal cells was lower compared with that of cancer cells (40). Further flow cytometry analysis demonstrated that AIL primarily arrested cells in the $G_{0} / G_{1}$ phase of the cell cycle and inhibited migration and invasion; however, this did not induce apoptosis. In addition, protein expression levels of Nrf2, YAP and c-Myc were decreased in the AIL-treatment group. Overall, Daga et al (40) demonstrated that AIL overcame cisplatin resistance in bladder cancer cells by downregulating the expression of $\mathrm{Nrf} 2$ and YAP, suggesting that AIL may be an effective drug for patients with bladder cancer that are resistant to chemotherapy.

Antitumor activity of AIL against lung cancer. Lung cancer is one of the most common malignancies in the world and is the leading cause of cancer-associated death, accounting for $18.4 \%$ of deaths among patients with cancer (5). Ni et al (42) screened 3,000 herbal monomers using an ATP luminescent high-throughput assay and demonstrated that AIL had the potential to inhibit the proliferation of non-small cell lung cancer (NSCLC) cells. AIL inhibited the proliferation and colony formation of NSCLC A549, H1299 and H1975 cells 


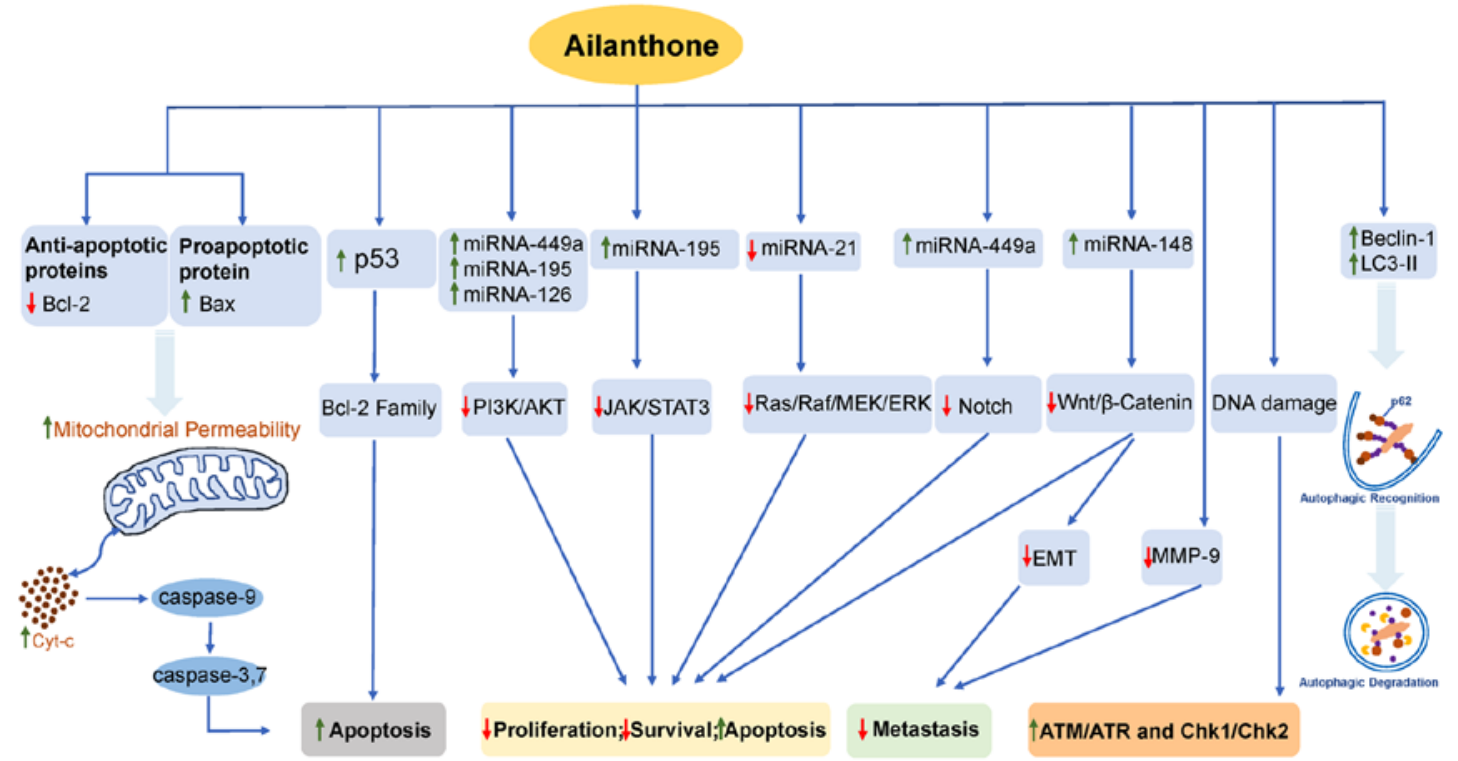

Figure 2. Antitumor mechanism of ailanthone. Green arrows indicates upregulation, and red arrows indicate downregulation of molecular targets. Bcl-2, B cell lymphoma-2; Bax, Bcl-2-associated X; mi, micro; PI3K, phosphoinositide 3-kinase; AKT, protein kinase B; JAK, Janus kinase; STAT3, signal transducer and activator of transcription 3; RAF, RAF proto-oncogene serine/threonine-protein kinase; MEK, mitogen-activated protein kinase; ERK, extracellular signal-regulated kinases; MMP-9, matrix metalloproteinase-9; EMT, epithelial mesenchymal transition; LC3, light chain 3; Cyt-c, cytochrome C.

in a dose- and time-dependent manner, and the growth inhibition ability of AIL was greater compared with that of cisplatin, which is a first-line chemotherapeutic drug for lung cancer (42). Orthotopic lung tumor models revealed that the volume and weight of tumors were smaller in the AIL-treated group. In addition, flow cytometry analysis demonstrated that AIL induced $\mathrm{G}_{1}$ or $\mathrm{G}_{2} / \mathrm{M}$ arrest of tumor cells in a dose-independent manner and induced apoptosis in H1975 cells, but did not induce apoptosis in A549 and H1299 cells (42). Western blotting showed that caspase-3 and poly-ADP-ribose polymerase (PARP) were activated in H1975 cells, but not in A549 and H1299 cells; similarly, following DAPI staining, AIL was observed to induce DNA damage in H1299 and H1975 cells, but not in A549 cells (42). This indicated that AIL-mediated growth inhibition was dependent on the induction of apoptosis and DNA damage. The authors further elucidated its mechanism of action using cDNA microarray analysis and reported that 1,222 genes were significantly differentially expressed in A549, H1299 and H1975 cells; among them, four genes, namely proliferating cell nuclear antigen ( $P C N A)$, replication protein A 1 (RPAl), acyl-CoA desaturase and DNA ligase 1 , were involved in both nucleotide excision repair and DNA replication signaling pathways (42). Subsequent experiments revealed that the mRNA levels of PCNA and RPA 1 were significantly decreased in all tested cell lines, while the protein expression levels of RPA1 were significantly decreased in a dose-dependent manner, and PCNA levels were not altered. Lastly, using animal experiments, it was confirmed that AIL inhibited subcutaneous xenograft and orthotopic lung tumor growth and prolonged the survival time of tumor-bearing mice (42). This indicated that AIL inhibited RPA1 expression in a dose-dependent manner, thus inhibiting DNA replication and tumor cell growth.

Hou et al (41) demonstrated that AIL inhibited the PI3K/AKT and Janus kinase (JAK)/signal transducer and activator of transcription (STAT)3 signaling pathways by increasing the expression levels of miR-195, as well as by promoting apoptosis and autophagy in the A549 lung cancer cell line. Abnormal expression of miR-195 is associated with the development and progression of numerous types of tumors, such as breast (65), lung (66), liver (67) and prostate cancer (68). The viability of A549 cells treated with different concentrations of AIL was significantly decreased $(\mathrm{P}<0.01$ or $\mathrm{P}<0.001)$ compared with that in the control group. Cell proliferation and cyclin D1 expression levels were also significantly decreased in cells treated with AIL $(\mathrm{P}<0.01)$, suggesting that AIL also inhibited the proliferation of lung cancer cells. Apoptotic analysis demonstrated that AIL significantly increased the rate of apoptosis of tumor cells, and the protein expression levels of cleaved-caspase-3 and -9 were increased, further indicating that AIL pomoted apoptosis (41). However, Ni et al (42) did not report that AIL induces apoptosis in A549 cells. Considering that a previous study identified that miR-195 was associated with lung cancer (66), Hou et al (41) detected the expression levels of miR-195 and the protein expression levels of autophagy-related proteins Beclin-1 and p62 rin AIL-treated A549 cells. It was concluded that AIL promoted apoptosis and autophagy by upregulating miR-195, which was verified by knockdown of miR-195. Also the upregulation of miR-195 inhibited the PI3K/AKT and JAK/STAT3 signaling pathways (41). Therefore, AIL was hypothesized to exert its anticancer effects by upregulating the expression of miR-195 in lung cancer.

Antitumor activity of AIL against gastric cancer. The incidence of gastric cancer in East Asia (including Mongolia, China, Japan and Korea) is notably higher compared with that in other regions, such as Northern America, Northern Europe, and Africa (5). Gastric cancer has become the fifth most frequently diagnosed cancer and the third leading cause of cancer-associated death in the world (5). Chen et al (43) 
explored the antitumor effect of AIL on human SGC-7901 gastric cancer cells. The results revealed that AIL inhibited the proliferation of SGC-7901 cells in a dose- and time-dependent manner. The $\mathrm{IC}_{50}$ value of AIL in SGC-7901 cells at $24 \mathrm{~h}$ was significantly $(\mathrm{P}<0.05)$ lower than that of the taxol group, which was used as a positive control. The apoptotic rate was also significantly $(\mathrm{P}<0.001)$ increased with increasing concentrations of AIL. Furthermore, AIL significantly increased the percentage of cells in the $\mathrm{G}_{2} / \mathrm{M}$ phase in a dose-dependent manner. The protein expression levels of Bcl-2 and Bax were down- and upregulated, respectively, in cells treated with AIL. Characteristic apoptotic morphology (nuclear shrinkage and chromatin condensation) were also observed in the AIL-treatment group following Hoechst 33258 staining, indicating that AIL induced apoptosis in SGC-7901 cells (43).

Antitumor activity of AIL against liver cancer. Liver cancer was the sixth most commonly diagnosed cancer and the fourth leading cause of cancer-associated death worldwide in 2018 (5). The incidence rate of liver cancer is often higher in countries with a lower Human Development Index (5). Primary liver cancer includes hepatocellular carcinoma (HCC), comprising $75-85 \%$ of total cases, intrahepatic cholangiocarcinoma, comprising $10-15 \%$ of cases, and other rare types (5). The 5 year survival rate of patients with liver cancer is still low ( 18\%), even following systemic treatment (69). Zhuo et al (44) investigated the anticancer effect of AIL in Huh7 human HCC cells. AIL reduced the viability of Huh7 cells in a dose- and time-dependent manner. Colony formation was also inhibited in a dose-dependent manner. Flow cytometry analysis showed that after $48 \mathrm{~h}$ of exposure to different concentrations of AIL $(0,0.2,0.4$, or $0.8 \mu \mathrm{M})$, the percentage of cells in the $\mathrm{G}_{0} / \mathrm{G}_{1}$ phase increased notably, confirming that AIL arrested the cell cycle. The expression levels of proteins regulating the cell cycle were investigated, and it was demonstrated that AIL decreased the expression of cyclins D and E, CDK2, CDK4 and CDK6, and increased the expression of p21 and p27 (44). The expression levels of cell division cycle 25A, which acts as an upstream regulator of the CDK/cyclin complex, and retinoblastoma protein $(\mathrm{Rb})$, which is a positive regulator of the cell cycle, were also significantly inhibited by AIL. In addition, AIL induced double-stranded DNA breakage and activated ataxia telangiectasia mutated proteins/ataxia telangiectasia, $\operatorname{Rad} 3$-assocaited proteins and $\mathrm{Chk1/Chk2}$ pathways in Huh7 cells, which may lead to $\mathrm{G}_{0} / \mathrm{G}_{1}$ cell cycle arrest (44). Furthermore, AIL also induced apoptosis of Huh7 cells in a dose-dependent manner, and significantly increased the levels of cleaved caspase- 9 and -3 , indicating that AIL can induce caspase-dependent apoptosis; in addition, AIL mediated apoptosis via the mitochondrial pathway, which was determined by detection of apoptosis-inducing factor and endonuclease $\mathrm{G}$ levels in the cytoplasm of Huh7 cells and the detection of decreased mitochondrial membrane potential (44). This study further revealed that AIL inhibited the PI3K/AKT signaling pathway using western blotting. Furthermore, the authors confirmed that AIL inhibited the growth and angiogenesis of Huh7 cell xenografts in nude mice, and its low toxicity was also verified (44). These results suggested that AIL exerted notable antitumor activity in Huh7 cells and may have potential as a novel drug for the treatment of HCC.
Antitumor activity of AIL against breast cancer. Breast cancer is the most commonly diagnosed cancer in the world, and was leading cause of cancer-associated death in women in 2018 (5). It has been reported that AIL significantly inhibits the proliferation of human MCF-7 breast cancer cells in a time- and dose-dependent manner (27). The inhibition rates of MCF-7 cells were $7.38-35.95,22.73-47.6$ and $35.64-56.76 \%$ at 24 , 48 and $72 \mathrm{~h}$, respectively, following treatment with different concentrations of AIL (0.5, 1.0, 2.0, 4.0 and $8.0 \mu \mathrm{g} / \mathrm{ml})(27)$. AIL also promoted apoptosis in a dose-dependent manner, and the apoptosis rate in the $8.0 \mu \mathrm{g} / \mathrm{ml}$ group was $75.51 \%$, which was significantly increased compared with that of the control group $(\mathrm{P}<0.01)$. In addition, the percentage of cells in $\mathrm{G}_{0} / \mathrm{G}_{1}$ phase were cells increased, whereas the percentage of cells in $\mathrm{S}$ and $\mathrm{G}_{2} / \mathrm{M}$ phase were notably decreased compared with that of the control group (27). In addition, the apoptosis of breast cancer MCF-7 cells in the AIL group was increased by upregulating the expression levels of Bax, caspase- 3 and downregulating the expression of $\mathrm{Bcl}-2$ (27). This indicated that AIL arrested the cell cycle and promoted apoptosis in breast cancer cells.

Gao et al (45) reported that AIL significantly reduced the viability of breast cancer cells, suppressed cell proliferation and induced apoptosis. AIL downregulated cyclin D1 and upregulated p53 and p21 protein levels in MDA-MB-231 cells (45). The $\mathrm{IC}_{50}$ of AIL on MDA-MB-231 cells was $9.8 \mu \mathrm{M}$ at $48 \mathrm{~h}$, which was lower compared with that of human non-tumorigenic breast epithelial MCF-12A cells; this indicated that AIL had lower cytotoxic effects on normal cells compared with that in cancer cells (45). In addition, AIL significantly decreased the percentage of BrdU-positive cells compared with the control group $(\mathrm{P}<0.05)$. An apoptosis assay revealed that AIL significantly increased the percentage of apoptotic cells, and AIL increased the protein levels of cleaved caspase-3 and $-9(\mathrm{P}<0.001)$. Transwell assay results revealed that AIL significantly reduced cell migration and invasion; also the levels of migration- and invasion-associated proteins MMP-9 and vimentin were significantly $(\mathrm{P}<0.05, \mathrm{P}<0.001)$ decreased in the AIL-treated group (45). The data from reverse transcription-quantitative PCR indicates that upregulation of miR-148a may mediate cell proliferation, apoptosis, migration and invasion affected by AIL in MDA-MB-231 cells. Furthermore, it was demonstrated that AIL inhibited AMP-activated protein kinase (AMPK) and Wnt/ $\beta$-catenin signaling pathway by regulating miR-148a in MDA-MB-231 cells (45). Overall, these two studies suggested that AIL had potential in the treatment of breast cancer.

Antitumor activity of AIL against VS. VS, also known as acoustic schwannoma, originates from the myelin-forming Schwann cells that surround the vestibular branches of the eighth (auditory) cranial nerve (70). VS accounts for 6-7\% of all intracranial tumors, $90 \%$ of which are located in the cerebellopontine angle (71). Yang et al (46) demonstrated the anticancer effect of AIL in human VS cells. AIL inhibited VS cell proliferation at $0.4,0.6,0.8$ and $1 \mu \mathrm{M}$ after 48 -h treatment, and promoted apoptosis in a dose-dependent manner via downregulation of miR-21. Administration of AIL significantly reduced the mRNA and protein expression 
levels of cyclin D1, which is a critical target of proliferative signals in the $\mathrm{G}_{1}$ phase to promote cell cycle progression (46). AIL significantly increased the apoptotic rate $(\mathrm{P}<0.001)$ and the expression levels of cleaved caspase- 9 and -3 . In addition, increased expression levels of the autophagy-associated proteins Beclin-1 and LC3-II, and decreased levels of p62 in the AIL group compared with those in the control cells suggested that AIL can promote the autophagy of VS cells (46). Previous studies have demonstrated that high levels of miR-21 expression are associated with several types of cancer (72-74), thus it was explored whether miR-21 functioned in AIL-mediated growth inhibition of VS cells. miR-21 levels were increased in VS cells compared with those in healthy tissue using microarray analysis techniques (46). AIL significantly decreased the levels of miR-21 in tumor cells $(\mathrm{P}<0.01)$, indicating that miR-21 was negatively regulated by AIL; overexpression of miR-21 reversed the aforementioned results, suggesting that miR-21 participated in the antitumor mechanism of AIL (46). Furthermore, the possible mechanism by which AIL induced apoptosis and autophagy in VS cells was explored, reporting that AIL blocked the Ras/RAF proto-oncogene serine/threonine-protein kinase (Raf)/mitogen-activated protein kinase kinase (MEK)/ERK and mTOR pathways in a miR-21-dependent manner (46). Therefore, these results demonstrated that AIL may be a potential antitumor agent for treating VS.

Antitumor activity of AIL against osteosarcoma. Statistics from 1973 to 2004 show that osteosarcoma is the most common primary malignant tumor of bone in children and adolescents in the United States (75). At present, complete surgical resection combined with chemotherapy is the primary method of treatment for osteosarcoma (76). A number of studies have demonstrated that abnormal expression of miRNA (miR-27a, 95-3p, 195 and 133b) was associated with osteosarcoma growth, metastasis and prognosis (77-79). For example, Kong et al (47) revealed that different concentrations of AIL inhibited MG63 osteosarcoma cell viability $(\mathrm{P}<0.01$ or $\mathrm{P}<0.001)$ and proliferation $(\mathrm{P}<0.01)$ compared with those in the control group by increasing the levels of miR-126. Furthermore, cell migration and invasion were also inhibited by AIL, whereas the rate of apoptosis was increased. Protein expression levels of cyclin D1 and Bcl-2 were decreased, while Bax, cleaved PARP and cleaved caspase-3 were increased following treatment of MG63 cells with AIL compared with untreated cells (47). In addition, PTEN protein expression levels were increased; however, PI3K and AKT phosphorylation levels were decreased (47). This indicated that the activation of the PI3K/AKT pathway was suppressed by AIL in MG63 cells. miR-126 was expressed at low levels in osteosarcoma cell lines MG63, U2OS, HOS and Saos-2 compared with those in normal osteoblast hFOB1 cells (47). These effects of AIL inducing MG63 cell proliferation, migration and invasion were all reversed when miR-126 was knocked down, indicating that AIL exerts its antiosteosarcoma effect by upregulating miR-126.

Antitumor activity of AIL against prostate cancer. In 2018, prostate cancer is the second most common type of cancer in the world and the fifth leading cause of cancer-associated death among men (5). Androgen deprivation therapy is the primary treatment for metastatic prostate cancer and includes three methods: Surgery, radiotherapy and castration drugs, such as Goserelin (80). Drug castration therapy primarily targets androgen receptors (ARs), which serve an important role in the development of prostate cancer. When ARs are phosphorylated following activation via endogenous androgen ligands (testosterone and dihydrotestosterone), the ligand-receptor complex, in association with

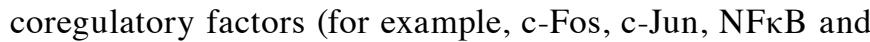
sex-determining region $\mathrm{Y}$ gene translocates into the nucleus and binds to specific genomic DNA regions to regulate target gene expression (81). Androgen binding is the most important stimulator of androgen receptor activation (81); therefore, drug castration therapy is primarily aimed at eliminating this stimulus. A previous study has reported that $>80 \%$ of patients respond to castration therapy in the early stages of treatment; however, almost all patients eventually progress to the terminal stage of castration-resistant prostate cancer (CRPC) (82). The drugs currently used in CRPC are docetaxel (83), cabazitaxel (84), abiraterone (85), radium-223 (86) and enzalutamide (87). In addition, the AR antagonist MDV3100 has also been reported to be effective against CRPC (88). Most of the AR antagonists used in clinic target the ligand-binding domain of the receptor. Therefore, AR shear variants (AR-Vs) that lack the ligand binding domain are resistant to antiandrogen therapy, including MDV3100 and abiraterone (89). He et al (48) demonstrated that AIL targeted p23 to overcome MDV3100 resistance in prostate cancer cell lines. The group used dihydrotestosterone to stimulate $22 \mathrm{RV} 1$ prostate cancer cells to activate the ligand-dependent receptor full-length AR (AR-FL), and transfected with AR1-651 (this segment of AR lacks a ligand-binding domain (LBD), but can be continuously activated to introduce AR-Vs. After 12-h incubation with various natural compounds, a dual luciferase assay was used to detect AR transcriptional activity, and it was observed that AIL effectively reduced the transcriptional activities of AR-FL and AR-Vs. The same results were also demonstrated in LNCaP and c4-2b prostate cancer cell lines (48). A sulforhodamine B assay confirmed that AIL inhibited the proliferation of several AR-positive prostate cancer cell lines, including LNCaP, c4-2b, 22RV1 and LAPC4. However, its proliferation inhibitory effect was weaker in AR-negative tumor cell lines and normal prostate cells (48). Similarly, AIL was more effective at inhibiting AR-positive cell migration compared with that of AR-negative prostate cancer cells. After combining AIL $(0.1 \mu \mathrm{M})$ with the AR antagonists bicalutamide (BIC) and MDV3100, c4-2b androgen-insensitive and 22RV1 castration-resistant cells proliferation was inhibited, indicating that AIL overcame drug resistance (48). AIL was also demonstrated to significantly inhibit the increase in tumor volume in 22RV1 xenografts in animal experiments with BALB/c nude mice. In addition, the oral bioavailability of AIL was $25.7 \%$ and did not exhibit significant hepatotoxicity; however, there was some damage to the gastric mucosa (48). Of note, $\mathrm{VCaP}$ xenografts were more sensitive to AIL compared with MDV3100. CRPC 22RV1 xenografts were resistant to BIC and MDV3100 treatment; however, AIL markedly inhibited tumor growth and reduced the tumor volume by $82 \%$ (95\% confidence intervals, 70-95\%) (48). 
AIL also significantly reduced the expression levels of AR proteins in LNCaP, 22RV1, LNCaP-MDV3100-R and VCaP prostate cancer cells in a dose-dependent manner, and these reductions were not associated with the presence or absence of androgen stimulation (48). An immunoprecipitation assay showed that AIL induced AR protein degradation and ubiquitination by preventing the interaction between AR and its molecular chaperones, heat shock protein HSP90 and HSP70; in addition, AIL downregulated AKT and CDK4 expression, which may be associated with inhibition of proliferation (48).

In the absence of a ligand, the AR resides in the cytosol bound to a complex of HS, chaperone and co-chaperone proteins (90). This protein complex is also termed foldosome and component proteins, including HSP90, HSP70 and p23, in which p23 serves an important role in maintaining the stability of the foldosome (90). Using the ProteOn XPR36 system, it was demonstrated that AIL could bind to p23 and inhibit its interaction with HSP90 in the foldosome, thus destabilizing the complex (90). In summary, targeting p23 is the main mechanism by which AIL induces the degradation of AR, and destabilizes the folding complex. Therefore, AIL is a potential candidate for the treatment of prostate cancer, which requires further investigation.

\section{Preclinical safety evaluation of AIL}

Unfortunately, most of the aforementioned studies did not evaluate the effect of AIL on normal cell lines $(27,37-40,43,46,47)$. Only a few studies have evaluated the cytotoxicity of AIL in normal cells or the toxicity and the side effects in animal models $(42,44,45,48)$. Gao et al (45) and He et al (48) have reported that cancer cells are more sensitive to AIL compared with normal cells. Traditional chemotherapeutic drugs have various side effects, such as myelosuppression, hepatotoxicity, nephrotoxicity, digestive tract reaction, neurotoxicity and pulmonary fibrosis, which markedly reduce the quality of life of patients with cancer and hinder the progress of treatment (91). Antitumor drugs extracted from traditional Chinese medicine exhibit less toxicity and fewer side effects compared with traditional chemotherapeutics. For example, Ni et al (42) demonstrated that AIL significantly inhibited NSCLC cell proliferation in vitro and tumor growth in vivo with low toxicity, and no damage was observed in the liver and kidney of SCID-Bg mice following AIL treatment. He et al (48) found that AIL does not induce significant hepatotoxicity in BALB/c nude mice; however, it can cause some damage to the stomach. To evaluate the in vivo cytotoxic effects of AIL, Zhuo et al (44) observed hematoxylin and eosin-stained sections from the heart, lung, liver, kidney and spleen and revealed no notable morphological changes were found in the AIL-treated animals.

In a recent study, Tang et al (92) used Kunming mice to evaluate the toxicity and safety of AIL. The acute toxicity experiments indicated that the main organs affected by AIL were the liver, spleen, intestine, colon and stomach. According to the toxicity of the classification standard, Globally Harmonized System of Classification and Labeling of Chemicals (93), the median lethal dose of AIL is $27.3 \mathrm{mg} / \mathrm{kg}$, which is level 2 (severe). The primary causes of death from AIL included gastrointestinal hemorrhage and liver steatosis (92). In addition, the toxicity of AIL in the blood system was also investigated; AIL significantly reduced the numbers of red blood cells (RBC), hemoglobin, hematocrit and mean corpuscular hemoglobin concentration and increase the MCN, RDWCV and platelet counts in mice; however, this process was reversed following drug withdrawal, indicating that AIL may have hematologic toxicity, but it was not the primary cause of death in mice (92). In the autopsy report, in addition to gastrointestinal hemorrhage and liver steatosis in the high concentration group, hepatic steatosis, cholestasis, splenomegaly and chronic gastritis were also observed in the low concentration treatment group. In addition, the study showed that AIL had reproductive toxicity, as the testis and epididymis of male mice had marked atrophy and pathological damage, while ovarian follicle development was hindered, with corpus luteum necrosis in female mice (92).

\section{Antitumor mechanism of AIL}

Effects on apoptosis. One of the antitumor effects of AIL is the activation of the apoptosis pathway. Apoptosis is a form of programmed cell death regulated by genes, through which abnormal cells in the body can be removed and to maintain homeostasis. Defects within apoptosis are associated with numerous diseases, such as autoimmunity, degenerative diseases and cancer (94). Dysregulation of apoptosis may lead to the formation of tumor cells (95). Therefore, molecular pathways that promote apoptosis have become effective targets against tumor growth. AIL has been demonstrated to induce apoptosis in numerous types of cancer cells via the intrinsic and extrinsic pathways by regulating multiple molecular targets $(37,43)$, including the caspase and Bcl-2 family proteins (43), transcription factors (such as $\beta$-catenin) (45), tumor suppressor genes (such as TP53) (45) and signaling pathways, such as PI3K/AKT (37) and JAK/STAT3 (41).

Members of the Bcl-2 family. The Bcl-2 family of proteins are key regulators of apoptosis via the mitochondrial apoptosis pathway and by promoting the caspase cascade activation $(96,97)$. The balanced ratio of various $\mathrm{Bcl}-2$ proteins determines whether the cell undergoes apoptosis or survives (98). AIL treatment downregulates Bcl-2 and upregulates Bax proteins in melanoma (37), gastric cancer (43), breast cancer (27) and osteosarcoma (47) cells. Mitochondrial membrane potential changes have been observed in melanoma (37) and hepatocellular carcinoma (44) cells treated with AIL compared with untreated cells, suggesting that the mitochondrial apoptosis pathway is involved.

TP53. The tumor suppressor protein $\mathrm{p} 53$, encoded by the TP53 gene in humans, serves an important role in preventing cancer development (99). TP53 is the most frequently mutated gene in human cancer (100). p53 can also promote apoptosis, relying on the induction of pro-apoptotic Bcl-2 proteins (99). In addition, p53 is an important mutual regulator of AMPK (101). AIL notably upregulated p53 protein levels in MDA-MB-231breast cancer cells, which promoted apoptosis (45).

\section{Effects on signaling pathways}

PI3K/AKT/mTOR signaling pathway. The PI3K/AKT/mTOR signaling pathway is one of the most important intracellular 
pathways that is frequently activated in a wide range of cancer types, including melanoma (102), breast cancer (103), lung and colorectal cancer (104). The PI3K/AKT/mTOR signaling pathway regulates cell proliferation, differentiation and metabolism, leading to anti-apoptosis and cancer cell survival. In addition, activation of the PI3K/AKT/mTOR pathway is also associated with tumor pathogenesis (including breast cancer, melanoma, gastric, lung, pancreatic and thyroid cancer and acute myeloid leukemia) and drug resistance, such as etoposide, DOX, cytarabine (105-107). PI3K, AKT or mTOR kinase inhibitors are already in clinical development $(102,104)$. It has been demonstrated that AIL treatment suppresses the PI3K/AKT/mTOR pathway by decreasing the phosphorylation of PI3K and AKT, thus inducing apoptosis. In melanoma (37), acute myeloid leukemia (38), lung cancer (41), liver cancer (44), VS (46) and osteosarcoma (47), AIL exerts its antitumor activity mainly by inhibiting the PI3K/AKT pathway.

JAK/STAT3 signaling pathway. The JAK/STAT3 signaling pathway serves a key role in cell survival and apoptosis; it is activated and its components are abnormally expressed in a variety of tumors, including leukemia (108), prostate cancer (109), renal cell carcinoma (110), lung (111), colon (112) and pancreatic cancer (113). In recent years, the JAK/STAT3 signaling pathway has been considered as a potential target for antitumor therapy (114). The phosphorylation of STAT3 increased in various types of cancer (109); therefore, analysis of p-STAT3 protein expression levels can be used to determine whether AIL acts on the JAK/STAT3 signaling pathway. A previous study has demonstrated that AIL exerts its antitumor effects on lung cancer by upregulating miR-195, which inhibits the JAK/STAT3 signaling pathway (41).

Ras/Raf/MEK/ERKsignalingpathway.TheRas/Raf/MEK/ERK signaling pathway also serves a pivotal role in tumor cell survival. Activation of the Ras protein is observed in $\sim 30 \%$ of human cancer types, including pancreatic, lung, endometrium, ovary, prostate, stomach, liver and breast cancer (115). ERK promotes survival, metastasis and cell proliferation, primarily by activating the epidermal growth factor receptor and Ras small guanosine triphosphatases; p-ERK translocates into the nucleus and regulates various transcription factors, such as the Ets family of transcription factors (116). In VS, AIL acts on this signaling pathway to exert its antitumor effects (46).

Wnt/ $\beta$-catenin signaling pathway. Dysregulation in the Wnt/ $\beta$-catenin pathway has been observed in numerous types of human cancer, such as colon cancer, melanoma, pancreas cancer and adrenocortical carcinoma (117). Wnt/ $\beta$-catenin is an important signal transduction pathway for the regulation of cell proliferation, apoptosis and metastasis (118). The expression levels of $\beta$-catenin are associated with poor prognosis in patients with breast cancer (119). Gao et al (45) reported that AIL inhibited the activation of the AMPK and Wnt/ $\beta$-catenin signaling pathways by regulating miR-148a in MDA-MB-231 cells.

Notch signaling pathway. Notch can function as a proto-oncogene in tumors, including breast cancer and lymphoid malignancies (for example $\mathrm{T}$ cell acute lymphoblastic leukemia, B cell chronic lymphocytic leukemia and splenic marginal zone lymphoma), and can also serve as a tumor suppressor gene (120). Notch signaling pathway is regulated at the transcriptional or post-transcriptional levels. The ubiquitination pathway, miRNA (including miR-1, -34, -146, -199 and -200) and Cyclin/Cdk complex can all affect the Notch signaling pathway (121). Notch is particularly important in the hematopoietic system (122). Notch mediates the proliferation, self-renewal and differentiation of stem and progenitor cells to generate mature cells in the blood (122). The activation of Notch signaling is associated with poor prognosis of patients with AML (123), and targeting Nocth1 has been considered as a novel strategy for AML treatment (124). AIL has been demonstrated to deactivate the Notch and PI3K/AKT signaling pathways by upregulating miR-449a expression (38).

Effects on cell proliferation and cell cycle. Cell proliferation is highly regulated in normal cells, and dysregulation of the cell cycle may lead to excessive or uncontrolled proliferation and promote metastasis (4). A number of studies have documented that AIL mediates its antiproliferative effect in cancer cells via modulation of various molecular targets, such as cyclin, CDKs, CDK inhibitors (CKIs) and the Rb gene (125). Cyclin binds to specific CDKs to form cyclin/CDK complexes that are important in regulating transcription, DNA repair, differentiation and apoptosis. The synthesis and destruction of cyclins is one of the primary means of regulating the cell cycle in vivo (125). CKI, as a negative regulator of the cell cycle, can be divided into two classes: The Ink4 family and the Cip/Kip family (126). AIL exerts its effects by regulating cyclin, CDK and CKI expression. Cyclins E and B were downregulated and p21 was upregulated in melanoma (37) and breast cancer (45), whereas cyclin D1 was downregulated in lung (41) and breast (45) cancer, VS (46) and osteosarcoma (47). In hepatocellular carcinoma, the expression levels of cyclins D and E were inhibited and CDK2, 4 and 6 were decreased, while the expression levels of p21 and p27 was increased (44). The expression of CDK4 was downregulated in prostate cancer (48). In addition, the $R b$ gene, one of the most important antioncogenes, can be phosphorylated by cyclin D/CDK4 or cyclin E/CDK2, releasing the transcription factor E2F. Transcription factor E2F regulates the expression of numerous genes, including cyclins $\mathrm{E}$ and $\mathrm{A}, c d k l$, $B-m y b$, dihydrofolate reductase, thymidine kinase and DNA polymerase (127). These genes serve an important role in the cell cycle and DNA synthesis $(127,128)$. AIL can also act on the retinoblastoma $(R b)$ gene in $\mathrm{HCC}$, reducing the expression of $\mathrm{Rb}$ protein, which is a positive regulator of the cell cycle (44).

Deregulation of cell metabolism and proliferation are major characteristics of tumor cells. AMPKs are activated when cells are metabolically stressed. AMPK activation regulates various cellular processes, such as cell proliferation, polarity, autophagy and apoptosis (129). Gao et al (45) demonstrated that AIL inhibited breast cancer cell proliferation by inhibiting AMPK.

Effects on autophagy. Autophagy serves a pivotal role in the cellular homeostasis of specific tissues, including liver tissue and skeletal muscle. Its functions include cell survival regulation (such as the response to metabolic alterations, recycling damaged macromolecules and organelles) and various forms of 


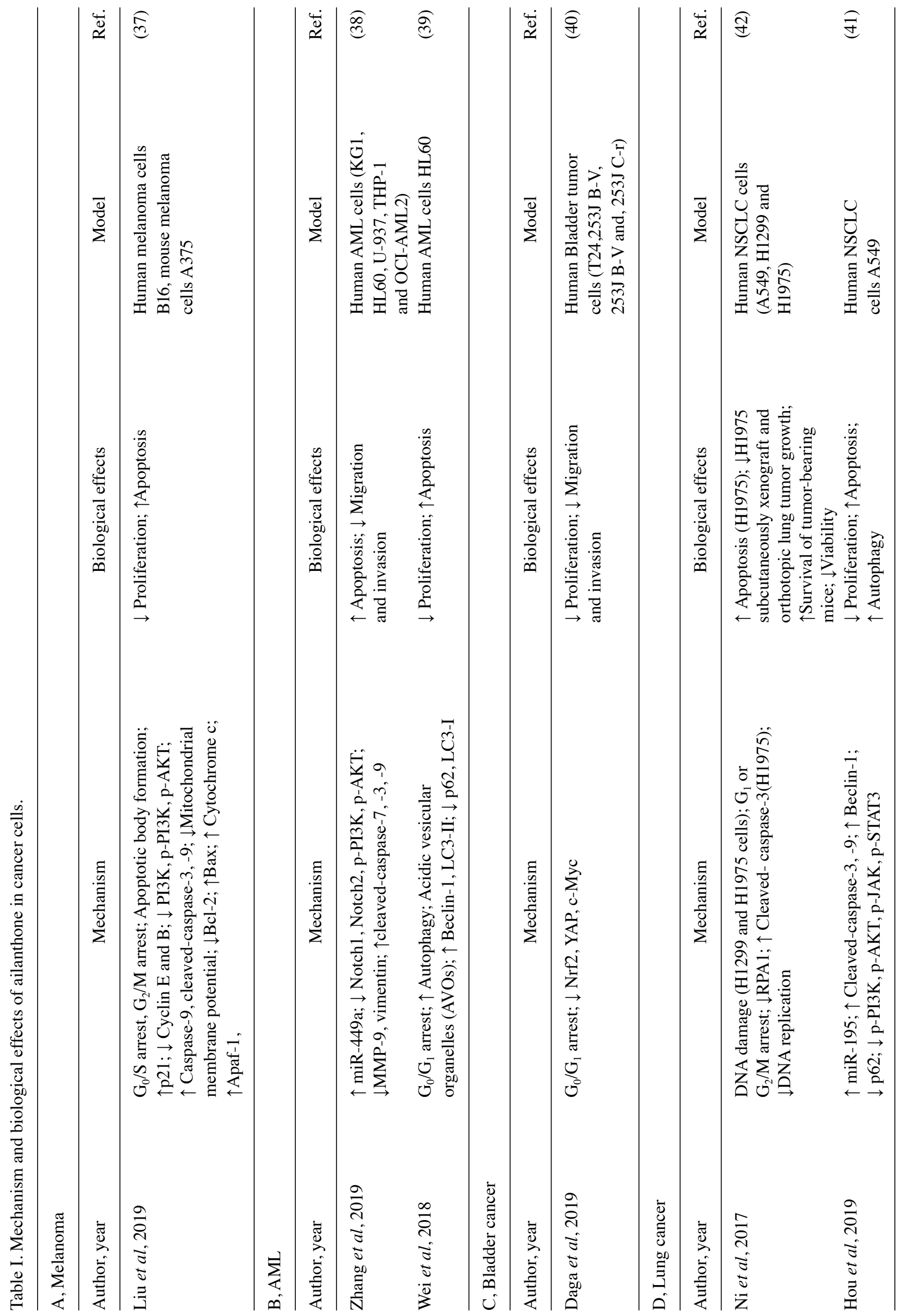




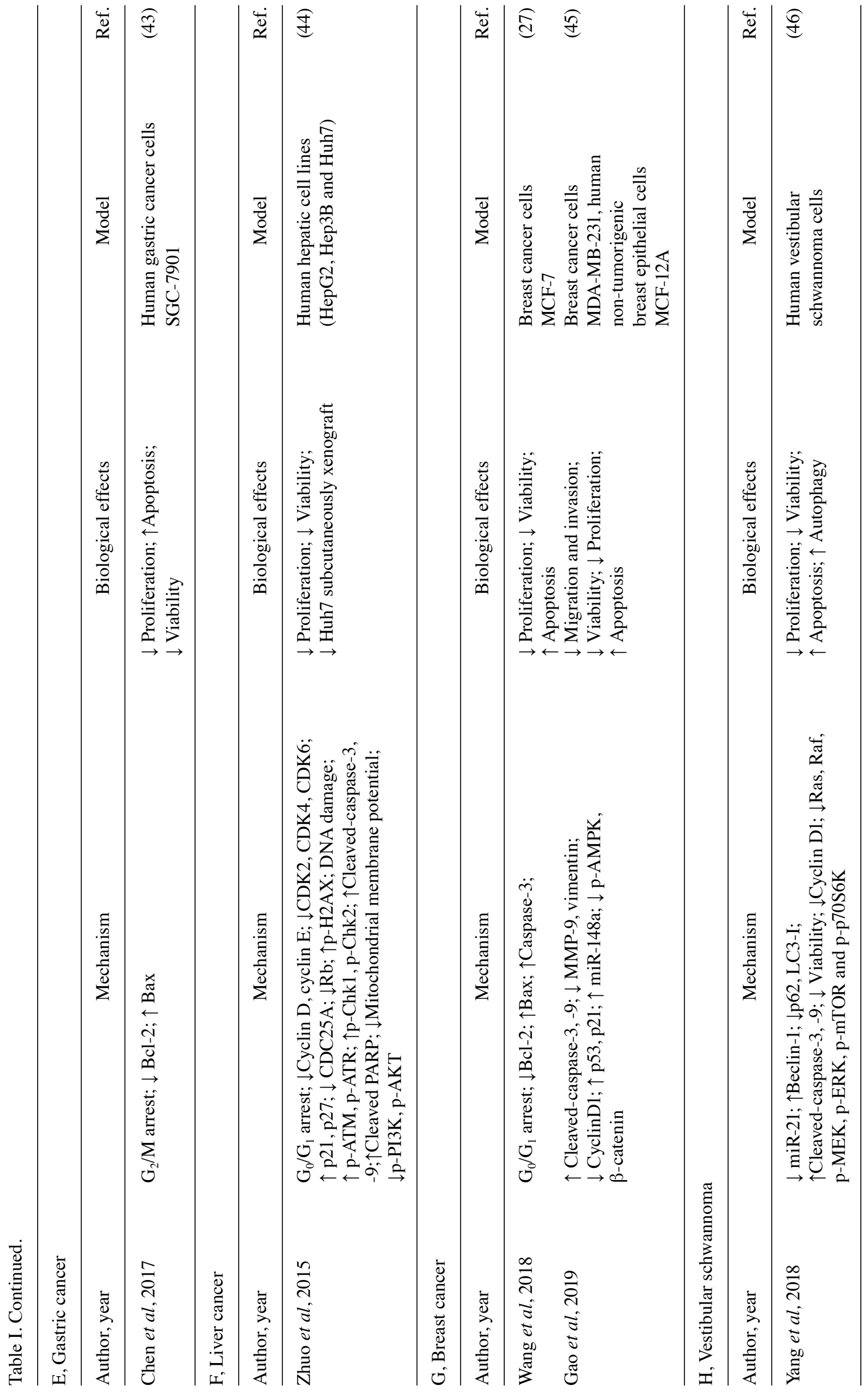




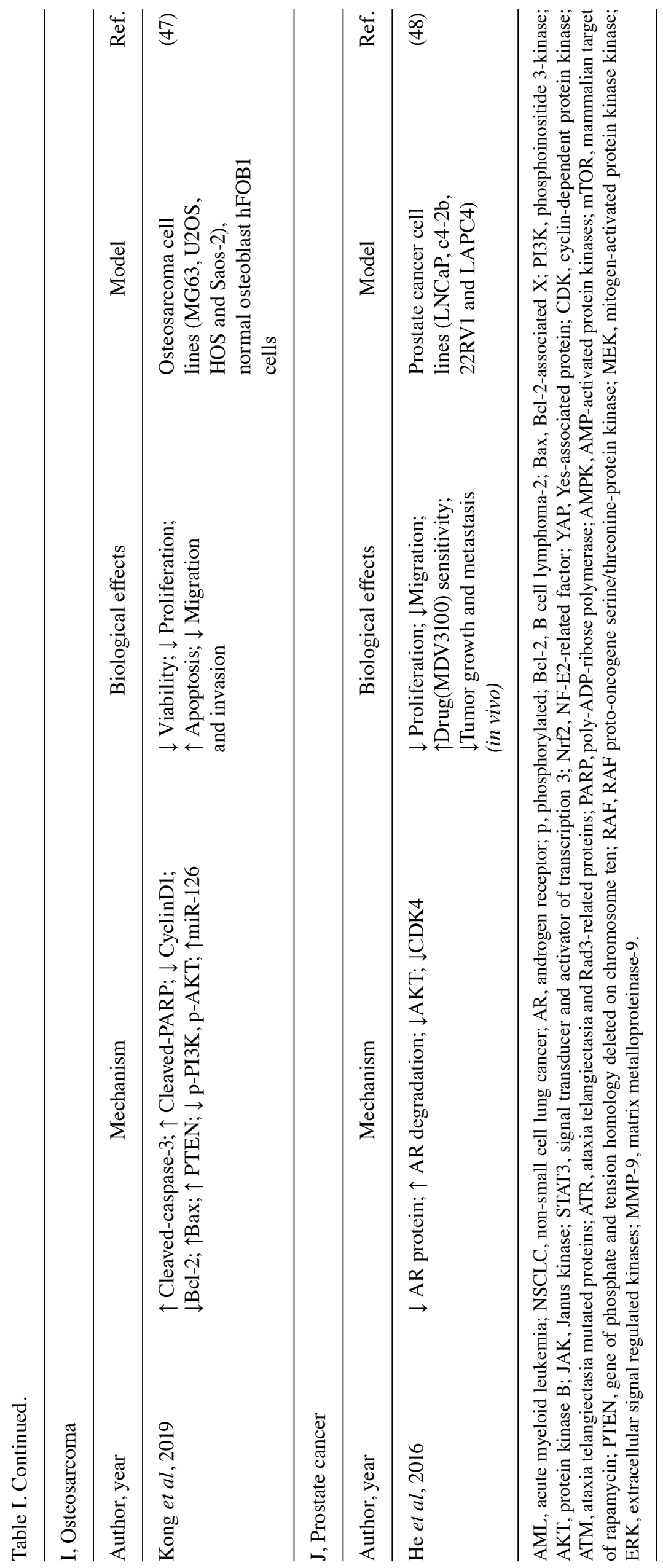


programmed cell death (130). Autophagy can be considered as a tumor-suppressing process in specific tissues (131). The detection of autophagy-associated proteins Beclin-1, p62 and LC3-I/II can be used to analyze the role of AIL in promoting autophagy (130). Beclin-1 serves an important role in the formation of autophagosomes, which can initiate autophagy by binding to type III phosphatidylinositol and triphosphate kinase, and is considered to be a marker of autophagy initiation (132). p62 is an adaptor molecule involved in the activation of autophagy, targeting polyubiquitinated protein aggregates to autophagic lysosomes and degrading autophagic lysosomes (133). Therefore, p62 expression levels are a reliable indicator of autophagy (133). LC3 protein is sheared at the carboxyl end by cysteine protease ATg4 with endonuclease activity, which exposes glycine residues and produces LC3-I localized in the cytoplasm (134). After being modified and processed by a ubiquitin-like system, including Atg7 and Atg3, LC3 is covalently bound to phosphatidylethanolamine to form LC3-II, which is localized to the autophagosome membrane (135). The LC3-I/II ratio can be used to assess the rate of autophagy (134). By detecting the aforementioned proteins, it was demonstrated that AIL induced autophagy in promyelocytic leukemia (39), lung cancer (41) and VS (46) cells.

Effects on cell invasion and metastasis. Invasion and metastasis occur in the moderate and advanced stages of various types of cancer $(136,137)$. As aforementioned, it has been shown that AIL inhibits metastasis in cancer cells by modulating molecular targets, including matrix metalloproteinases (MMPs). MMPs can degrade various protein components in the extracellular matrix, destroy the histological barrier of tumor cell invasion and serve a key role in tumor invasion and metastasis (138). Overexpression of MMPs, particularly MMP-2 (gelatinase A) and MMP-9 (gelatinase B) has been associated with tumor progression, metastasis and poor prognosis in breast, lung, colon, gastric, pancreatic, and prostate cancer (139). Zhang et al (38) and Gao et al (45) demonstrated that the inhibitory effect of AIL on invasion and migration of breast cancer cells and acute myeloid leukemia cells was associated with decreased MMP-9 expression.

Effects on drug resistance. Tumor chemotherapy is often accompanied by drug resistance difficulties. It has been demonstrated that traditional Chinese medicine plant extracts, such as curcumin (140), matrine (141) and resveratrol (142), can improve drug resistance and reduce the use of chemotherapy drugs. He et al (48) also confirmed that AIL improved resistance to MDV3100 in prostate cancer cell lines.

\section{Conclusions}

The antitumor effect of AIL involves numerous mechanisms (Table I); however, the current research on the underlying mechanisms of AIL function is still relatively superficial. Based on existing studies, it has been observed in few studies in this review that the advantages of AIL as an antitumor agent are its relatively low toxicity and fewer side effects compared with existing chemotherapeutic drugs $(42,44,48)$. However, it cannot be ignored that the median lethal dose in mice observed by Tang et al (92) was rated as level 2 (severe). Considering that the research investigating AIL is still in its infancy, there are few comparative studies on the efficacy of AIL and existing chemotherapy drugs. Therefore, this conclusion remains to be verified. Furthermore, the majority of studies lack in vivo experiments and clinical trials, and there are no further studies on the bioavailability and side effects of AIL. Therefore, in subsequent studies, researchers should focus on the efficacy of AIL compared with existing chemotherapy drugs, as well as in vivo and clinical trials. It is hypothesized that in the future, when its efficacy is demonstrated to be favorable compared with existing chemotherapy, AIL may be used as an effective novel anticancer treatment.

\section{Acknowledgements}

Not applicable.

\section{Funding}

This study was funded by the Traditional Chinese Medicine Science and Technology Project of Zhejiang Province (grant no. 2018ZA109), Medical and Health Science and Technology Project of Zhejiang Province (grant no. 2018ZH026), Natural Science Foundation of Ningbo (grant nos. 2016A610157 and 2018A610371) and the Science and Technology Projects of Zhejiang Province (grant no. LGF19H030007).

\section{Availability of data and materials}

Not applicable.

\section{Authors' contributions}

HD and ZY conceived and designed the study and prepared the manuscript. $\mathrm{XY}, \mathrm{CH}, \mathrm{KG}$ and $\mathrm{XL}$ were responsible for the literature search, data visualization and analysis. XL and YJ searched for the relevant literature and revised the manuscript. All authors read and approved the final manuscript.

\section{Ethics approval and consent to participate}

Not applicable.

\section{Patient consent for publication}

Not applicable.

\section{Competing interests}

The authors declare that they have no competing interests.

\section{References}

1. Blattner WA: Human retroviruses: Their role in cancer. Proc Assoc Am Physicians 111: 563-572, 1999.

2. Tomlinson IP, Novelli MR and Bodmer WF: The mutation rate and cancer. Proc Natl Acad Sci USA 93: 14800-14803, 1996.

3. Wogan GN, Hecht SS, Felton JS, Conney AH and Loeb LA: Environmental and chemical carcinogenesis. Semin Cancer Biol 14: 473-486, 2004.

4. Hanahan D and Weinberg RA: Hallmarks of cancer: The next generation. Cell 144: 646-674, 2011. 
5. Bray F, Ferlay J, Soerjomataram I, Siegel RL, Torre LA and Jemal A: Global cancer statistics 2018: GLOBOCAN estimates of incidence and mortality worldwide for 36 cancers in 185 countries. CA Cancer J Clin 68: 394-424, 2018.

6. Chen W, Zheng R, Zhang S, Zhang S, Zeng H, Xia C, Zuo T, Yang Z, Zou X and He J: Cancer incidence and mortality in China, 2013. Cancer Lett 401: 63-71, 2017.

7. Tseng $\mathrm{HH}$ and $\mathrm{He} \mathrm{B}$ : Molecular markers as therapeutic targets in lung cancer. Chin J Cancer 32: 59-62, 2013.

8. Qi F, Zhao L, Zhou A, Zhang B, Li A, Wang Z and Han J: The advantages of using traditional Chinese medicine as an adjunctive therapy in the whole course of cancer treatment instead of only terminal stage of cancer. Biosci Trends 9: 16-34, 2015

9. Nakamura K, Shinozuka K and Yoshikawa N: Anticancer and antimetastatic effects of cordycepin, an active component of cordyceps sinensis. J Pharmacol Sci 127: 53-56, 2015.

10. Lumlerdkij N, Tantiwongse J, Booranasubkajorn S, Boonrak R, Akarasereenont $\mathrm{P}$, Laohapand $\mathrm{T}$ and Heinrich M: Understanding cancer and its treatment in thai traditional medicine: An ethnopharmacological-anthropological investigation. J Ethnopharmacol 216: 259-273, 2018.

11. Bezwoda WR, MacDonald DF, Gear JS, Derman DP, Bothwell TH, Sqi S, Hurwitz S and Lewis D: Combination chemotherapy including bleomycin in the treatment of advanced hodgkin's disease. S Afr Med J 53: 369-373, 1978

12. Durant JR, Gams RA, Bartolucci AA and Dorfman RF: BCNU with and without cyclophosphamide, vincristine, and prednisone (COP) and cycle-active therapy in non-hodgkin's lymphoma. Cancer Treat Rep 61: 1085-1096, 1977.

13. Wong MY and Chiu GN: Liposome formulation of co-encapsulated vincristine and quercetin enhanced antitumor activity in a trastuzumab-insensitive breast tumor xenograft model. Nanomedicine 7: 834-840, 2011.

14. Munker S, Vogelhuber M, Bornschein J, Stroszczynski C, Evert M, Schlitt H, Herr W and Teufel A: EpiCO (epirubicin, cyclophosphamide and vincristine) as treatment for extrapulmonary high-grade neuroendocrine neoplasms. Z Gastroenterol 58: $133-136,2020$.

15. Büyükkapu Bay S, Kebudi R, Görgün $\mathrm{O}$, Zülfikar B, Darendeliler E and Çakır FB: Vincristine, irinotecan, and temozolomide treatment for refractory/relapsed pediatric solid tumors: A single center experience. J Oncol Pharm Pract 25 1343-1348, 2019.

16. Weaver BA: How taxol/paclitaxel kills cancer cells. Mol Biol Cell 25: 2677-2681, 2014

17. Caparica R, Bruzzone M, Poggio F, Ceppi M, de Azambuja E and Lambertini M: Anthracycline and taxane-based chemotherapy versus docetaxel and cyclophosphamide in the adjuvant treatment of HER2-negative breast cancer patients: A systematic review and meta-analysis of randomized controlled trials. Breast Cancer Res Treat 174: 27-37, 2019.

18. Reck M, Brahmer J, Bennett B, Taylor F, Penrod JR, DeRosa M Dastani H, Spigel DR and Gralla RJ: Evaluation of health-related quality of life and symptoms in patients with advanced non-squamous non-small cell lung cancer treated with nivolumab or docetaxel in checkmate 057. Eur J Cancer 102: 23-30, 2018.

19. da Rocha AB, Lopes RM and Schwartsmann G: Natural products in anticancer therapy. Curr Opin Pharmacol 1: 364-369, 2001.

20. Wang P, Yang HL, Yang YJ, Wang L and Lee SC: Overcome cancer cell drug resistance using natural products. Evid Based Complement Alternat Med 2015: 767136, 2015.

21. Wu X, Kong W, Qi X, Wang S, Chen Y, Zhao Z, Wang W, Lin X, Lai J, Yu Z and Lai G: Icariin induces apoptosis of human lung adenocarcinoma cells by activating the mitochondrial apoptotic pathway. Life Sci 15: 116879, 2019.

22. Zhang P, Zhang M, Yu D, Liu W, Hu L, Zhang B, Zhou Q and Cao Z: Lycorine inhibits melanoma cell migration and metastasis mainly through reducing intracellular levels of beta-catenin and matrix metallopeptidase 9. J Cell Physiol 234: 10566-10575, 2019.

23. Segun PA, Ismail FMD, Ogbole OO, Nahar L, Evans AR, Ajaiyeoba $O$ and Sarker SD: Acridone alkaloids from the stem bark of citrus aurantium display selective cytotoxicity against breast, liver, lung and prostate human carcinoma cells. J Ethnopharmacol 227: 131-138, 2018.

24. Tomar P, Dey YN, Sharma D, Wanjari MM, Gaidhani S and Jadhav A: Cytotoxic and antiproliferative activity of kanchnar guggulu, an ayurvedic formulation. J Integr Med 16: 411-417, 2018.

25. Dhiman K: Ayurvedic intervention in the management of uterine fibroids: A case series. Ayu 35: 303-308, 2014

26. Kasymjanova G, Tran AT, Cohen V, Pepe C, Sakr L, Small D, Agulnik JS and Jagoe RT: The use of a standardized Chinese herbal formula in patients with advanced lung cancer: A feasibility study. J Integr Med 16: 390-395, 2018.
27. Wang R, Lu Y, Li H, Sun L, Yang N, Zhao M, Zhang M and Shi Q: Antitumor activity of the ailanthus altissima bark phytochemical ailanthone against breast cancer MCF-7 cells. Oncol Lett 15: 6022-6028, 2018

28. Rahman S, Fukamiya N, Ohno N, Tokuda H, Nishino H, Tagahara, Lee KH and Okano M: Inhibitory effects of quassinoid derivatives on epstein-barr virus early antigen activation. Chem Pharm Bull (Tokyo) 45: 675-677, 1997.

29. Cho SK, Jeong M, Jang DS and Choi JH: Anti-Inflammatory effects of canthin-6-one alkaloids from ailanthus altissima. Planta Med 84: 527-535, 2018.

30. Okunade AL, Bikoff RE, Casper SJ, Oksman A, Goldberg DE and Lewis WH: Antiplasmodial activity of extracts and quassinoids isolated from seedlings of ailanthus altissima (Simaroubaceae). Phytother Res 17: 675-677, 2003.

31. Jin M, Yang JH, Lee E, Lu Y, Kwon S, Son KH, Son KH, Son JK and Chang HW: Antiasthmatic activity of luteolin-7-O-glucoside from Ailanthus altissima through the downregulation of $\mathrm{T}$ helper 2 cytokine expression and inhibition of prostaglandin E2 production in an ovalbumin-induced asthma model. Biol Pharm Bull 32: 1500-1503, 2009.

32. Rahman S, Fukamiya N, Okano M, Tagahara K and Lee KH Anti-Tuberculosis activity of quassinoids. Chem Pharm Bull (Tokyo) 45: 1527-1529, 1997.

33. Melanchauski LS, Broto AP, Moraes TM, Nasser ALM, Said A, Hawas UW, Rashed K, Vilegas W and Hiruma-Lima CA: Gastroprotective and antisecretory effects of ailanthus excelsa (Roxb). J Nat Med 64: 109-113, 2010.

34. Wright CW, O'Neill MJ, Phillipson JD and Warhurst DC: Use of microdilution to assess in vitro antiamoebic activities of brucea javanica fruits, simarouba amara stem, and a number of quassinoids. Antimicrob Agents Chemother 32: 1725-1729, 1988

35. Kundu P and Laskar S: A brief resume on the genus Ailanthus: Chemical and pharmacological aspects. Phytochem Rev 9: 379-412, 2010.

36. Kato T, Suzumura Y, Fukushima M, Honda T, Nakanishi T and Noguchi T: Antitumor activity of novel ailanthone derivatives in vitro and in vivo. Anticancer Res 8: 573-579, 1988.

37. Liu W, Liu X, Pan Z, Wang D, Li M, Chen X, Zhou L, Xu M, Li D and Zheng Q: Ailanthone induces cell cycle arrest and apoptosis in melanoma B16 and A375 cells. Biomolecules 9: 275, 2019.

38. Zhang Y,Zhang C and Min D: Ailanthone up-regulates miR-449a to restrain acute myeloid leukemia cells growth, migration and invasion. Exp Mol Pathol 108: 114-120, 2019.

39. Wei C, Chen C, Cheng Y, Zhu L, Wang Y, Luo C, He Y, Yang Z and Ji Z: Ailanthone induces autophagic and apoptotic cell death in human promyelocytic leukemia HL-60 cells. Oncol Lett 16 3569-3576, 2018.

40. Daga M, Pizzimenti S, Dianzani C, Cucci MA, Cavalli R, Grattarola M, Ferrara B, Scariot V, Trotta F and Barrera G: Ailanthone inhibits cell growth and migration of cisplatin resistant bladder cancer cells through down-regulation of Nrf2, YAP, and c-Myc expression. Phytomedicine 56: 156-164, 2019.

41. Hou S, Cheng Z, Wang W, Wang $X$ and $\mathrm{Wu} Y$ : Ailanthone exerts an antitumor function on the development of human lung cancer by upregulating microRNA-195. J Cell Biochem 120: 10444-10451, 2019.

42. Ni Z, Yao C, Zhu X, Gong C, Xu Z, Wang L, Li S, Zou C and Zhu S: Ailanthone inhibits non-small cell lung cancer cell growth through repressing DNA replication via downregulating RPA1. Br J Cancer 117: 1621-1630, 2017

43. Chen Y, Zhu L, Yang X, Wei C, Chen C, He Y and Ji Z: Ailanthone induces G2/M cell cycle arrest and apoptosis of SGC7901 human gastric cancer cells. Mol Med Rep 16: 6821-6827, 2017.

44. Zhuo Z, Hu J, Yang X, Chen M, Lei X, Deng L, Yao N, Peng Q, Chen Z, Ye W and Zhang D: Ailanthone inhibits huh7 cancer cell growth via cell cycle arrest and apoptosis in vitro and in vivo. Sci Rep 5: 16185, 2015.

45. Gao W, Ge S and Sun J: Ailanthone exerts anticancer effect by up-regulating miR-148a expression in MDA-MB-231 breast cancer cells and inhibiting proliferation, migration and invasion. Biomed Pharmacother 109: 1062-1069, 2019.

46. Yang P, Sun D and Jiang F: Ailanthone promotes human vestibular schwannoma cell apoptosis and autophagy by downregulation of miR-21. Oncol Res 26: 941-948, 2018

47. Kong D, Ying B, Zhang J and Ying H: The anti-osteosarcoma property of ailanthone through regulation of miR-126/VEGF-A axis. Artif Cells Nanomed Biotechnol 47: 3913-3919, 2019.

48. He Y, Peng S, Wang J, Chen H, Cong X, Chen A, Hu M, Qin M, Wu H, Gao S, et al: Ailanthone targets p23 to overcome MDV3100 resistance in castration-resistant prostate cancer. Nat Commun 7: $13122,2016$. 
49. Han F, Liu G, Sun C and Wei J: Ailanthone reverses multidrug resistance by inhibiting the P-glycoprotein-mediated efflux in resistant K562/A02 cells. Cell Mol Biol (Noisy-le-grand) 64: 55-61, 2018.

50. Guy GP Jr, Thomas CC, Thompson T, Watson M, Massetti GM, Richardson LC; Centers for Disease Control and Prevention (CDC): Vital signs: Melanoma incidence and mortality trends and projections - United States, 1982-2030. MMWR Morb Mortal Wkly Rep 64: 591-596, 2015.

51. Lens MB and Dawes M: Global perspectives of contemporary epidemiological trends of cutaneous malignant melanoma. $\mathrm{Br}$ J Dermatol 150: 179-185, 2004

52. Yamamoto JF and Goodman MT: Patterns of leukemia incidence in the United States by subtype and demographic characteristics, 1997-2002. Cancer Causes Control 19: 379-390, 2008.

53. Shin VY and Chu KM: miRNA as potential biomarkers and therapeutic targets for gastric cancer. World J Gastroenterol 20: 10432-10439, 2014

54. Chen YJ, Guo YN, Shi K, Huang HM, Huang SP, Xu WQ Li ZY, Wei KL, Gan TQ and Chen G: Down-Regulation of microRNA-144-3p and its clinical value in non-small cell lung cancer: A comprehensive analysis based on microarray, miRNA-sequencing, and quantitative real-time PCR data. Respir Res 20: 48, 2019.

55. Yuan G,Zhao Y,Wu D, Gao C and Jiao Z: miRNA-20a upregulates TAK1 and increases proliferation in osteosarcoma cells. Future Oncol 14: 461-469, 2018.

56. De Luca L, Trino S, Laurenzana I, Tagliaferri D, Falco G, Grieco V, Bianchino G, Nozza F, Campia V, D'Alessio F, et al: Knockdown of miR-128a induces Lin28a expression and reverts myeloid differentiation blockage in acute myeloid leukemia. Cell Death Dis 8: e2849, 2017.

57. Elhamamsy AR, El Sharkawy MS, Zanaty AF, Mahrous MA, Mohamed AE and Abushaaban EA: Circulating miR-92a, miR-143 and miR-342 in plasma are novel potential biomarkers for acute myeloid leukemia. Int J Mol Cell Med 6: 77-86, 2017.

58. Li Q, Peng J, Li X, Leng A and Liu T: MiR-449a targets Flot2 and inhibits gastric cancer invasion by inhibiting TGF-beta-mediated EMT. Diagn Pathol 10: 202, 2015.

59. Sandbothe M, Buurman R, Reich N, Greiwe L, Vajen B, Gürlevik E, Schäffer V, Eilers M, Kühnel F, Vaquero A, et al: The microRNA-449 family inhibits TGF-beta-mediated liver cancer cell migration by targeting SOX4. J Hepatol 66: 1012-1021, 2017.

60. DeGeorge KC,Holt HR and Hodges SC: Bladder cancer: Diagnosis and treatment. Am Fam Physician 96: 507-514, 2017.

61. Nadal R and Bellmunt J: Management of metastatic bladder cancer. Cancer Treat Rev 76: 10-21, 2019.

62. Ciamporcero E, Daga M, Pizzimenti S, Roetto A, Dianzani C, Compagnone A, Palmieri A, Ullio C, Cangemi L, Pili R and Barrera G: Crosstalk between Nrf2 and YAP contributes to maintaining the antioxidant potential and chemoresistance in bladder cancer. Free Radic Biol Med 115: 447-457, 2018.

63. Rojo de la Vega M, Chapman E and Zhang DD: NRF2 and the hallmarks of cancer. Cancer Cell 34: 21-43, 2018.

64. Zanconato F, Cordenonsi M and Piccolo S: YAP/TAZ at the roots of cancer. Cancer Cell 29: 783-803, 2016.

65. Wang Y, Zhang X, Zou C, Kung HF, Lin MC, Dress A, Wardle F, Jiang BH and Lai L: miR-195 inhibits tumor growth and angiogenesis through modulating IRS1 in breast cancer. Biomed Pharmacother 80: 95-101, 2016.

66. Liu B, Qu J, Xu F, Guo Y, Wang Y, Yu H and Qian B: miR-195 suppresses non-small cell lung cancer by targeting CHEK1. Oncotarget 6: 9445-9456, 2015.

67. Yu S, Jing L, Yin XR, Wang MC, Chen YM, Guo Y, Nan KJ and Han LL: miR-195 suppresses the metastasis and epithelial-mesenchymal transition of hepatocellular carcinoma by inhibiting YAP Oncotarget 8: 99757-99771, 2017.

68. Zhang X, Tao T, Liu C, Guan H, Huang Y, Xu B and Chen M: Downregulation of miR-195 promotes prostate cancer progression by targeting HMGA1. Oncol Rep 36: 376-382, 2016.

69. Siegel RL, Miller KD and Jemal A: Cancer statistics, 2018. CA Cancer J Clin 68: 7-30, 2018

70. Brackmann DE: Vestibular schwannoma (acoustic neuroma). Otolaryngol Clin North Am 45: xiii-xv, 2012.

71. Rosahl S, Bohr C, Lell M, Hamm K and Iro H: Diagnosis and management of vestibular schwannomas - an interdisciplinary challenge. Laryngorhinootologie 96: S152-S182, 2017 (In German).

72. Feng YH, Wu CL, Tsao CJ, Chang JG, Lu PJ, Yeh KT, Uen YH Lee JC and Shiau AL: Deregulated expression of sprouty2 and microRNA-21 in human colon cancer: Correlation with the clinical stage of the disease. Cancer Biol Ther 11: 111-121, 2011.
73. Wu X, Zhuo S, Zheng C and Gao G: MicroRNA-21 correlates TGF-beta1 pathway of pancreatic ductal adenocarcinoma. Zhong Nan Da Xue Xue Bao 44: 749-756, 2019 (In Chinese).

74. Bharali D, Banerjee BD, Bharadwaj M, Husain SA and Kar P: Expression analysis of microrna-21 and microrna-122 in hepatocellular carcinoma. J Clin Exp Hepatol 9: 294-301, 2019.

75. Mirabello L, Troisi RJ and Savage SA: Osteosarcoma incidence and survival rates from 1973 to 2004: Data from the surveillance, epidemiology, and end results program. Cancer 115: 1531-1543, 2009.

76. Harrison DJ, Geller DS, Gill JD, Lewis VO and Gorlick R: Current and future therapeutic approaches for osteosarcoma. Expert Rev Anticancer Ther 18: 39-50, 2018.

77. Kim YH, Goh TS, Lee CS, Oh SO, Kim JI, Jeung SH and Pak K: Prognostic value of microRNAs in osteosarcoma: A meta-analysis. Oncotarget 8: 8726-8737, 2017.

78. Hesse $\mathrm{E}$ and Taipaleenmaki H: MicroRNAs in bone metastasis. Curr Osteoporos Rep 17: 122-128, 2019.

79. Sasaki R, Osaki M and Okada F: MicroRNA-Based diagnosis and treatment of metastatic human osteosarcoma. Cancers 11:553, 2019.

80. Huggins C and Hodges CV: Studies on prostatic cancer. I. The effect of castration, of estrogen and androgen injection on serum phosphatases in metastatic carcinoma of the prostate. CA Cancer J Clin 22: 232-240, 1972.

81. Koochekpour S: Androgen receptor signaling and mutations in prostate cancer. Asian J Androl 12: 639-657, 2010.

82. Harris WP, Mostaghel EA, Nelson PS and Montgomery B: Androgen deprivation therapy: Progress in understanding mechanisms of resistance and optimizing androgen depletion. Nat Clin Pract Urol 6: 76-85, 2009.

83. Petrylak DP, Tangen CM, Hussain MH, Lara PN Jr, Jones JA, Taplin ME, Burch PA, Berry D, Moinpour C, Kohli M, et al: Docetaxel and estramustine compared with mitoxantrone and prednisone for advanced refractory prostate cancer. N Engl J Med 351: 1513-1520, 2004.

84. de Bono JS, Oudard S, Ozguroglu M, Hansen S, Machiels JP, Kocak I, Gravis G, Bodrogi I, Mackenzie MJ, Shen L, et al: Prednisone plus cabazitaxel or mitoxantrone for metastatic castration-resistant prostate cancer progressing after docetaxel treatment: A randomised open-label trial. Lancet 376: 1147-1154, 2010.

85. Ryan CJ,Smith MR,Fizazi K, Saad F,Mulders PFA,Sternberg CN, Miller K, Logothetis CJ, Shore ND, Small EJ, et al: Abiraterone acetate plus prednisone versus placebo plus prednisone in chemotherapy-naive men with metastatic castration-resistant prostate cancer (COU-AA-302): final overall survival analysis of a randomised, double-blind, placebo-controlled phase 3 study. Lancet Oncol 16: 152-160, 2015.

86. Parker C, Nilsson S, Heinrich D, Helle SI, O'Sullivan JM, Fosså SD, Chodacki A, Wiechno P, Logue J, Seke M, et al: Alpha emitter radium-223 and survival in metastatic prostate cancer. $\mathrm{N}$ Engl J Med 369: 213-223, 2013.

87. Beer TM, Armstrong AJ, Rathkopf DE, Loriot $Y$, Sternberg CN, Higano CS, Iversen P, Bhattacharya S, Carles J, Chowdhury S, et al: Enzalutamide in metastatic prostate cancer before chemotherapy. N Engl J Med 371: 424-433, 2014.

88. Scher HI, Fizazi K, Saad F, Taplin ME, Sternberg CN, Miller K, de Wit R, Mulders P, Chi KN, Shore ND, et al: Increased survival with enzalutamide in prostate cancer after chemotherapy. N Engl J Med 367: 1187-1197, 2012.

89. Antonarakis ES, Lu C, Wang H, Luber B, Nakazawa M, Roeser JC, Chen Y, Mohammad TA, Chen Y, Fedor HL, et al: AR-V7 and resistance to enzalutamide and abiraterone in prostate cancer. N Engl J Med 371: 1028-1038, 2014.

90. Cano LQ, Lavery DN and Bevan CL: Mini-Review: Foldosome regulation of androgen receptor action in prostate cancer. Mol Cell Endocrinol 369: 52-62, 2013.

91. Tao WW, Jiang H, Tao XM, Jiang P, Sha LY and Sun XC: Effects of acupuncture, tuina, tai chi, qigong, and traditional Chinese medicine five-element music therapy on symptom management and quality of life for cancer patients: A meta-analysis. J Pain Symptom Manage 51: 728-747, 2016.

92. Tang S, Ma X, Lu J, Zhang Y, Liu M and Wang X: Preclinical toxicology and toxicokinetic evaluation of ailanthone, a natural product against castration-resistant prostate cancer, in mice. Fitoterapia 136: 104161, 2019.

93. Winder C, Azzi R and Wagner D: The development of the globally harmonized system (GHS) of classification and labelling of hazardous chemicals. J Hazard Mater 125: 29-44, 2005.

94. Hassan M, Watari H, AbuAlmaaty A, Ohba Y and Sakuragi N: Apoptosis and molecular targeting therapy in cancer. BioMed Res Int 2014: 150845, 2014. 
95. Goldar S, Khaniani MS, Derakhshan SM and Baradaran B Molecular mechanisms of apoptosis and roles in cancer development and treatment. Asian Pac J Cancer Prev 16: 2129-2144, 2015

96.Green DR and Reed JC: Mitochondria and apoptosis. Science 281: 1309-1312, 1998

97. Redza-Dutordoir M and Averill-Bates DA: Activation of apoptosis signalling pathways by reactive oxygen species. Biochim Biophys Acta 1863: 2977-2992, 2016.

98. Cory S, Roberts AW, Colman PM and Adams JM: Targeting BCL-2-like proteins to kill cancer cells. Trends Cancer 2: 443-460, 2016.

99. Lowe SW, Schmitt EM, Smith SW, Osborne BA and Jacks T: P53 is required for radiation-induced apoptosis in mouse thymocytes. Nature 362: 847-849, 1993.

100. Kastenhuber ER and Lowe SW: Putting p53 in context. Cell 170: 1062-1078, 2017.

101. Wang Z, Wang N, Liu P and Xie X: AMPK and cancer. Exp Suppl 107: 203-226, 2016.

102. Aziz SA, Jilaveanu LB, Zito C, Camp RL, Rimm DL, Conrad P and Kluger HM: Vertical targeting of the phosphatidylinositol-3 kinase pathway as a strategy for treating melanoma. Clin Cancer Res 16: 6029-6039, 2010.

103. Brachmann SM, Hofmann I, Schnell C, Fritsch C, Wee S, Lane H, Wang S, Echeverria CG and Maira SM: Specific apoptosis induction by the dual PI3K/mTor inhibitor NVP-BEZ235 in HER2 amplified and PIK3CA mutant breast cancer cells Proc Natl Acad Sci USA 106: 22299-22304, 2009.

104. Martinelli E, Troiani T, D'Aiuto E, Morgillo F, Vitagliano D, Capasso A, Costantino S, Ciuffreda LP, Merolla F, Vecchione L, et al: Antitumor activity of pimasertib, a selective MEK 1/2 inhibitor, in combination with PI3K/mTOR inhibitors or with multi-targeted kinase inhibitors in pimasertib-resistant human lung and colorectal cancer cells. Int J Cancer 133: 2089-2101, 2013.

105. Lim HJ, Crowe P and Yang JL: Current clinical regulation of PI3K/PTEN/Akt/mTOR signalling in treatment of human cancer. J Cancer Res Clin Oncol 141: 671-689, 2015.

106. Hassan B, Akcakanat A, Holder AM and Meric-Bernstam F: Targeting the PI3-kinase/Akt/mTOR signaling pathway. Surg Oncol Clin N Am 22: 641-664, 2013.

107. Panda $\mathrm{M}$ and Biswal BK: Cell signaling and cancer: A mechanistic insight into drug resistance. Mol Biol Rep 46: 5645-5659, 2019.

108. Koskela HL, Eldfors S, Ellonen P, van Adrichem AJ Kuusanmäki H, Andersson EI, Lagström S, Clemente MJ, Olson T, Jalkanen SE, et al: Somatic STAT3 mutations in large granular lymphocytic leukemia. N Engl J Med 366: 1905-1913, 2012.

109. Cocchiola R, Rubini E, Altieri F, Chichiarelli S, Paglia G, Romaniello D, Carissimi S, Giorgi A, Giamogante F, Macone A, et al: STAT3 post-translational modifications drive cellular signaling pathways in prostate cancer cells. Int J Mol Sci 20: 815, 2019.

110. Horiguchi A, Oya M, Shimada T, Uchida A, Marumo K and Murai M: Activation of signal transducer and activator of transcription 3 in renal cell carcinoma: A study of incidence and its association with pathological features and clinical outcome. J Urol 168: 762-765, 2002.

111. Zhu H, Chang LL, Yan FJ, Hu Y, Zeng CM, Zhou TY, Yuan T, Ying MD, Cao J, He QJ and Yang B: AKR1C1 activates STAT3 to promote the metastasis of non-small cell lung cancer. Theranostics 8: 676-692, 2018.

112. Nishimoto A, Kugimiya N, Hosoyama T, Enoki T, Li TS and Hamano K: JAB1 regulates unphosphorylated STAT3 DNA-binding activity through protein-protein interaction in human colon cancer cells. Biochem Biophy Res Commun 438: 513-518, 2013

113. Wei D, Le X, Zheng L, Wang L, Frey JA, Gao AC, Peng Z, Huang S, Xiong HQ, Abbruzzese JL and Xie K: Stat3 activation regulates the expression of vascular endothelial growth factor and human pancreatic cancer angiogenesis and metastasis. Oncogene 22: 319-329, 2003.

114. Wu M, Song D, Li H, Yang Y, Ma X, Deng S, Ren C and Shu X: Negative regulators of STAT3 signaling pathway in cancers. Cancer Manag Res 11: 4957-4969, 2019.

115. Stirewalt DL, Kopecky KJ, Meshinchi S, Appelbaum FR, Slovak ML, Willman CL and Radich JP: FLT3, RAS, and TP53 mutations in elderly patients with acute myeloid leukemia. Blood 97: 3589-3595, 2001.

116. Roberts PJ and Der CJ: Targeting the Raf-MEK-ERK mitogen-activated protein kinase cascade for the treatment of cancer. Oncogene 26: 3291-3310, 2007.

117. Polakis P: Wnt signaling in cancer. Cold Spring Harb Perspect Biol 4: a008052, 2012.
118. Tan SH and Barker N: Wnt signaling in adult epithelial stem cells and cancer. Prog Mol Biol Transl Sci 153: 21-79, 2018.

119. Taketo MM: Shutting down wnt signal-activated cancer. Nat Genet 36: 320-322, 2004

120. Radtke F and Raj K: The role of Notch in tumorigenesis: Oncogene or tumour suppressor? Nat Rev Cancer 3: 756-767, 2003.

121. Huang T, Zhou Y, Cheng AS, Yu J, To KF and Kang W: NOTCH receptors in gastric and other gastrointestinal cancers: Oncogenes or tumor suppressors? Mol Cancer 15: 80, 2016.

122. Lobry C, Oh P, Mansour MR, Look AT and Aifantis I: Notch signaling: Switching an oncogene to a tumor suppressor. Blood 123: 2451-2459, 2014.

123. Xu X, Zhao Y, Xu M, Dai Q, Meng W, Yang J and Qin R: Activation of Notch signal pathway is associated with a poorer prognosis in acute myeloid leukemia. Med Oncol 28: S483-S489, 2011.

124. Ono M, Takimoto R, Osuga T, Okagawa Y, Hirakawa M, Yoshida M, Arihara Y, Uemura N, Hayasaka N, Miura S, et al: Targeting notch-1 positive acute leukemia cells by novel fucose-bound liposomes carrying daunorubicin. Oncotarget 7: 38586-38597, 2016.

125. Johnson DG and Walker CL: Cyclins and cell cycle checkpoints. Ann Rev Pharmacol Toxicol 39: 295-312, 1999.

126. Vermeulen K, Van Bockstaele DR and Berneman ZN: The cell cycle: A review of regulation, deregulation and therapeutic targets in cancer. Cell Prolif 36: 131-149, 2003.

127. Geng Y, Eaton EN, Picon M, Roberts JM, Lundberg AS, Gifford A, Sardet C and Weinberg RA: Regulation of cyclin E transcription by E2Fs and retinoblastoma protein. Oncogene 12: 1173-1180, 1996.

128. Ohtani K, DeGregori J and Nevins JR: Regulation of the cyclin E gene by transcription factor E2F1. Proc Natl Acad Sci USA 92: 12146-12150, 1995

129. Luo Z, Zang M and Guo W: AMPK as a metabolic tumor suppressor: Control of metabolism and cell growth. Future Oncol 6: 457-470, 2010.

130. Galluzzi L, Bravo-San Pedro JM, Levine B, Green DR and Kroemer G: Pharmacological modulation of autophagy: Therapeutic potential and persisting obstacles. Nat Rev Drug Discov 16: 487-511, 2017.

131. Choi KS: Autophagy and cancer. Exp Mol Med 44: 109-120, 2012.

132. Liang XH, Jackson S, Seaman M, Brown K, Kempkes B, Hibshoosh $\mathrm{H}$ and Levine B: Induction of autophagy and inhibition of tumorigenesis by beclin 1. Nature 402: 672-676, 1999.

133. Komatsu M, Waguri S, Koike M, Sou YS, Ueno T, Hara T, Mizushima N, Iwata JI, Ezaki J, Murata S, et al: Homeostatic levels of p62 control cytoplasmic inclusion body formation in autophagy-deficient mice. Cell 131: 1149-1163, 2007.

134. Tanida I, Minematsu-Ikeguchi N, Ueno T and Kominami E: Lysosomal turnover, but not a cellular level, of endogenous LC3 is a marker for autophagy. Autophagy 1: 84-91, 2005.

135. Tanida I, Ueno T and Kominami E: LC3 and Autophagy. Methods Mol Biol 445: 77-88, 2008.

136. Mundade R, Imperiale TF, Prabhu L, Loehrer PJ and Lu T: Genetic pathways, prevention, and treatment of sporadic colorectal cancer. Oncoscience 1: 400-406, 2014.

137. Coleman MP: Cancer survival: Global surveillance will stimulate health policy and improve equity. Lancet 383: 564-573, 2014

138. Winer A, Adams S and Mignatti P: Matrix metalloproteinase inhibitors in cancer therapy: Turning past failures into future successes. Mol Cancer Ther 17: 1147-1155, 2018.

139. Hung WC, Tseng WL, Shiea J and Chang HC: Skp2 overexpression increases the expression of MMP-2 and MMP-9 and invasion of lung cancer cells. Cancer Lett 288: 156-161, 2010.

140. Karthika C and Sureshkumar R: Can curcumin along with chemotherapeutic drug and lipid provide an effective treatment of metastatic colon cancer and alter multidrug resistance? Med Hypotheses 132: 109325, 2019.

141. An Q, Han C, Zhou Y, Li F, Li D, Zhang X, Yu Z, Duan Z and Kan Q: Matrine induces cell cycle arrest and apoptosis with recovery of the expression of miR-126 in the A549 non-small cell lung cancer cell line. Mol Med Rep 14: 4042-4048, 2016.

142. Bjorklund M, Roos J, Gogvadze V and Shoshan M: Resveratrol induces SIRT1- and energy-stress-independent inhibition of tumor cell regrowth after low-dose platinum treatment. Cancer Chemother Pharmacol 68: 1459-1467, 2011.

This work is licensed under a Creative Commons Attribution-NonCommercial-NoDerivatives 4.0 International (CC BY-NC-ND 4.0) License. 